\title{
SEXUAL BEHAVIOUR OF EPILEPTICS- A BIOPSYCHOSOCIAL STUDY IN RURAL SOUTH INDIA
}

\author{
Viswanathan G. A1, Ananda Krishna Kumar $S^{2}$, Sabesan $S^{3}$
}

${ }^{1}$ Assistant Professor, Department of Psychiatry, Madurai Medical College.

${ }^{2}$ Associate Professor, Department of Psychiatry, Madurai Medical College.

${ }^{3}$ Retd. Professor and HOD, Department of Psychiatry, Madurai Medical College.

\section{ABSTRACT}

\section{BACKGROUND}

Epilepsy related changes in sexual behaviour include hyposexuality, hypersexuality and paraphilias. Like in any other physical illness, psychological factors and ethnic health beliefs modulate the expression of sexuality. Patients with epilepsy during their treatment were focused only about their frequency of seizures, effective control of recurrence and prophylactic treatment of future episodes. Their personal, social and occupational functioning capacity are disregarded and their psychological reactions are not given prominence in clinical management. Sexuality being a suppressed issue culturally, impact of physical and psychological issues concerning sexual behaviour is ignored.

The present study is concerned with understanding the dynamic interplay of various factors in the manifest of sexual behaviour of the epileptics.

\section{MATERIALS AND METHODS}

The study consisted in long-term follow-up of 42 consenting adult epileptics and their sexual partners using 'own control' methods. Excluding those with neurological or other biological disturbances, the present pattern of sexual behaviour was compared to premorbid functioning. Desire, frequency, alteration in patterns, sexual dysfunctions and post-coital disturbances were enquired into and causative factors were explored.

\section{RESULTS}

Analysis revealed that all patients continued to have the same desire level. Disturbances were more in men and were due to psychological factors stemming from native health belief systems. Reduced frequency, changes in pattern and sexual dysfunctions including male erectile dysfunction and premature orgasm were all aetiologically correlated to such anxieties. Attribution of physical weakness to both seizures and loss of semen, beliefs about 'nervous damage' in epilepsy causing sexual disturbances, avoidance of epileptic patients due to fear of contagion and expiation for the 'divine curse' were the prevalent belief systems.

\section{CONCLUSION}

Understanding the dynamics of aetiology enabled an early and easy resolution of the problem. Adequate psychoeducation and counselling of patients with their partners will make few changes in their intimacy and quality of life.

\section{KEYWORDS}

Epilepsy - Sexual Behaviour - Health Beliefs - Psychodynamics of Altered Sexual Behaviour.

HOW TO CITE THIS ARTICLE: Viswanathan GA, Kumar AKS, Sabesan S. Sexual behaviour of epileptics- a biopsychosocial study in rural South India. J. Evolution Med. Dent. Sci. 2017;6(25):2092-2096, DOI: 10.14260/Jemds/2017/455

\section{BACKGROUND}

Sexual behaviour constitutes the central and yet the secret theme of adulthood. Through sexuality, individuals define themselves, particularly in marital relations which form the basis for the family, the fundamental social institution. The biopsychosocial dimensions of sexual behaviour have evolved to become less hormone-dependent and in humans sexuality is essentially neuro-psychologically programmed.[1],[2] Personality traits, cultural norms and ethnic belief systems contextualise individual variations in conceptualisation, execution and consequences of sexuality.[3]

Financial or Other, Competing Interest: None.

Submission 20-02-2017, Peer Review 17-03-2017,

Acceptance 22-03-2017, Published 27-03-2017.

Corresponding Author:

Dr. Ananda Krishna Kumar $S$

Plot No. 14, Muthamil Nagar

$3^{\text {rd }}$ Street, $P \&$,

Madurai-625017.

E-mail:dr.anandakrish@gmail.com

DOI: $10.14260 /$ jemds $/ 2017 / 455$
Expression of sexuality during physical illness and its significance to the individual depend more on the belief systems, except when biological basis of sexual behaviour is compromised.[4]

Altered sexual behaviour among the epileptics has been attributed to disruption of normal limbic functions by epileptic discharges, altered pituitary and gonadal hormones, alteration of behaviour and hormones by Antiepileptic Drugs (AEDs) and social and psychological factors.[5] Interictal sexual abnormalities include hypersexuality, paraphilias and hyposexuality[6][7] and were associated more often with temporal lobe foci, poor seizure control and depressive symptoms.[8] Hormonal changes, particularly those due to AEDs were related to subclinical hypogonadotropic hypogonadism. ${ }^{[8][9]}$ But Jensen et al[10] using a biopsychosocial approach concluded that epilepsy did not increase the risk of sexual dysfunction in males or females. Sexual dysfunctions might result from social and psychological factors disturbing sexual responsiveness.[5][11] Transcultural studies revealed that behavioural morbidity in epilepsy has been significantly related to obviously non- 
scientific perception of its causes, social consequences of epilepsy and the sanctioned illness-behaviour.[12] Complex interaction between native health beliefs, personal experiences and seizure pattern culminate in manifest sexual behaviour.

The present study aims to know the nature of variations in sexual behaviour of epileptics, prevalence of the pattern of changes, the influencing factors and the psychodynamics of the disturbances.

\section{MATERIALS AND METHODS}

The study was conducted in Department of Psychiatry, Madurai Medical College from Jan. 2004 to December 2005 after obtaining permission from Ethical Committee. Being a sensitive area of enquiry, confidentiality was central to the interview. Patients and partners were included in the study after obtaining informed consent. There was an understandable level of contamination with false claims, unrealistic expectations and hesitation to dwell upon certain areas of interpersonal relations. But they were minimised by long periods of prospective followup, waiting for them to open up, interview with sexual partners and offering help when needed. Reliability of the data could always be verified with collaborative history from the partner. Moral teaching, advocacy of cultural norms, etc. were never allowed to inhibit the interview.

The study was a naturalistic one and aimed more at qualitative data. A detailed proforma included sociodemographic variables, nature of seizure disorder, details of pharmacological management, details of present sexual behaviour in comparison to that prior to the onset of seizures and nature of dysfunctions if any. Their conceptual correlation between seizure and sexual behaviour was explored. When the information was adequate and reliable, the patients were included in the study on the following inclusion criteria:

1. An adult suffering from seizure disorder and his/her sexual partner willing to share details of sexual functioning.

2. Patient should be suffering from generalised tonic-clonic seizures. History, clinical neurological assessment, Skiagram of skull, EEG, neuroimaging studies, etc. should not reveal any lateralising or localising signs. Patient and partner should not suffer from any andrological or gynaecological problems.

3. Patient should not be suffering from substance abuse or other psychiatric problems, except those comorbid to epilepsy.

Investigations of sexual functions such as Doppler studies, Rigiscan or Cavernosography were not done on all patients, as they were rejected by some of the patients as 'costly,' 'not needed' or 'embarrassing.' The following operational definitions were used in the study:

- Frequency: Frequency with both spouse and extramarital partner if any were taken into consideration.
- Posture: Granting normal variations, the most commonly preferred posture was considered.

- Deviance: Whenever any alteration in sexual behaviour was consistently resisted and yet was demanded of compliance by direct or indirect coercion, it was classified as deviance.

Sample was selected randomly and included for the study, who gave consent for the study. Those who were hesitant to discuss intimate matters and were not interested were excluded from the study. Total of 42 patients which is inclusive of 27 men and 15 women with their spouses were followed up and assessed according to operational design. In consideration of the naturalistic research design and qualitative nature of the data, simple statistical methods such as enumeration, $\chi^{2}$ and Fisher's Exact Probability Test were used in the analysis of the data.

\section{RESULTS}

The sample was chosen over a long period of time. All patients had been married and their sexual relations had taken a regular pattern prior to the onset of seizure disorder. Subsequent alterations were compared against the established individual norms. During the study period wife of one patient had left him, but she had been interviewed in detail previously. Confidence and openness of the interview were evident when even extramarital relations of patients or their spouses could be discussed with ease.

Only patients with GTCS were chosen, because motor seizures were what socio-culturally perceived as epilepsy. None of them had clinical evidence of neurological impairment and all had normal skiagrams of skull. EEG and CT scan of the brain could be done only in 31 and 29 patients respectively. Only one patient had abnormal EEG record, but no lateralising or localising features were present. None of the CT scans showed structural changes. None of them evinced clinically significant cognitive disturbances or psychotic changes. Except for occasional situation related depressive states and an acceptable level of anxiety in the context of the illness, no other psychiatric abnormality was evident. Eleven men occasionally used alcohol, but none to the level of dependence and 16 men smoked from five to twenty beedis per day. Penile Doppler (4 patients), Rigiscan (7 Patients) and Cavernosography (1 Patient) did not reveal any abnormality. Nineteen patients were on Carbamazepine (400 mgs to 800 mgs per day), three on Sodium Valproate (500 mgs to 1000 mgs per day), 10 patients on Diphenylhydantoin (200 mgs to $400 \mathrm{mgs}$ per day) and others on combination of drugs. None of them had any adverse effects due to drugs.

Out of the total of 42 patients, 15 were women. As the pattern of sexual behaviour, socio-cultural norms and role in sexual act were vastly different, details of men and women were seen separately. Their socio-demographic details and seizure pattern were as given in Table 1 . 


\begin{tabular}{|c|c|c|c|c|}
\hline & \multirow{2}{*}{$\begin{array}{c}\text { Men } \\
(n=27)\end{array}$} & \multirow{2}{*}{$\begin{array}{l}\text { Women } \\
(n=15)\end{array}$} & \multicolumn{2}{|c|}{ Total $(\mathrm{N}=42)$} \\
\hline & & & $\mathbf{n}$ & $\%$ \\
\hline Age & & & & \\
\hline Below 30 yrs. & 02 & 09 & 11 & 26 \\
\hline 30 to 45 yrs. & 16 & 06 & 22 & 52 \\
\hline Above 45 yrs. & 09 & 00 & 09 & 22 \\
\hline Literacy & & & & \\
\hline Below 5 yrs. & 14 & 07 & 21 & 50 \\
\hline 5 to 10 yrs. & 08 & 07 & 15 & 36 \\
\hline More than 10 yrs. & 05 & 01 & 06 & 14 \\
\hline Domicile & & & & \\
\hline Rural & 18 & 09 & 27 & 64 \\
\hline Urban & 09 & 06 & 15 & 36 \\
\hline GTCS Frequency & & & & \\
\hline $\begin{array}{c}\text { Less than once in } 6 \\
\text { months }\end{array}$ & 09 & 09 & 18 & 43 \\
\hline Once in 2 to 6 months & 13 & 04 & 17 & 40 \\
\hline More than once in 2 & & & & \\
\hline months & 05 & 02 & 07 & 17 \\
\hline GTCS Duration & & & & \\
\hline Less than 5 yrs. & 02 & 09 & 11 & 26 \\
\hline 5 to 10 yrs. & 15 & 04 & 19 & 45 \\
\hline More than 10 yrs. & 10 & 02 & 12 & 29 \\
\hline $\begin{array}{r}\text { Table } 1 \\
\text { Illnes }\end{array}$ & 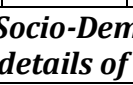 & rap & & \\
\hline
\end{tabular}

Five men had voluntarily abstained between 2 to 9 years and reasoned that loss of energy during sex would further weaken them. Three women patients had a 'forced abstinence' for 6 yrs., because of their husband's fear of contagion despite medical advice to the contrary. Hence, alteration in pattern of sexual behaviour was studied only in 34 patients (Table 2). Out of 22 men, only one did not evince any change in sexual behaviour compared to 6 out of 12 women $\left(\chi^{2}=8.13 ; \mathrm{df}=1 ; \mathrm{p}<0.001\right)$. Change in frequency was the most prominent observation and in all six women alterations in sexual behaviour entailed only changes in frequency.

\begin{tabular}{|c|c|c|c|}
\hline & $\begin{array}{c}\text { Men } \\
(n=22)\end{array}$ & $\begin{array}{l}\text { Women } \\
(n=12)\end{array}$ & \begin{tabular}{|c|} 
Statistical \\
Significance
\end{tabular} \\
\hline $\begin{array}{c}\text { Change of Posture } \\
\text { Present } \\
\text { Absent }\end{array}$ & $\begin{array}{l}04 \\
18\end{array}$ & $\begin{array}{l}00 \\
12\end{array}$ & $\sigma=0.16$ \\
\hline $\begin{array}{c}\text { Deviance } \\
\text { Present } \\
\text { Absent }\end{array}$ & $\begin{array}{l}06 \\
16\end{array}$ & $\begin{array}{l}00 \\
12\end{array}$ & $\sigma=0.06$ \\
\hline $\begin{array}{c}\text { Changes in Desire } \\
\text { Present } \\
\text { Absent }\end{array}$ & $\begin{array}{l}00 \\
22\end{array}$ & $\begin{array}{l}00 \\
12\end{array}$ & \\
\hline $\begin{array}{c}\text { Changes in Preparatory } \\
\text { Phase } \\
\text { Present } \\
\text { Absent }\end{array}$ & $\begin{array}{l}10 \\
12\end{array}$ & $\begin{array}{l}00 \\
12\end{array}$ & $\sigma=0.005$ \\
\hline $\begin{array}{c}\text { Orgasmic Dysfunction- } \\
\text { Premature } \\
\text { Present } \\
\text { Absent }\end{array}$ & $\begin{array}{l}04 \\
18\end{array}$ & $\begin{array}{l}00 \\
12\end{array}$ & $\sigma=0.16$ \\
\hline $\begin{array}{c}\text { Orgasmic Dysfunction- } \\
\text { Incompetence } \\
\text { Present } \\
\text { Absent }\end{array}$ & $\begin{array}{l}00 \\
22\end{array}$ & $\begin{array}{l}00 \\
12\end{array}$ & \\
\hline
\end{tabular}

\begin{tabular}{|c|c|c|c|}
\hline $\begin{array}{c}\text { Post Coital Symptoms } \\
\text { Present }\end{array}$ & 00 & 00 & \\
Absent & 22 & 12 & \\
\hline $\begin{array}{c}\text { Extramarital Relations } \\
\text { of Spouse }\end{array}$ & 02 & 10 & $\chi^{2}=\mathbf{1 5 . 6 3}$ \\
Present & 20 & 02 & \\
Absent & & & \\
\hline \multicolumn{2}{|c|}{ Table 2. Changes in Sexual Behaviour of Patients* } \\
\hline
\end{tabular}

*Excludes 2 men and one woman who were abstinent. $\sigma$ refers to Fisher's exact probability test.

Figures given in bold are statistically significant.

Alterations in pattern of sexual behaviour were marked by their absence among women patients. Among men patients, four demanded a persistent 'woman-above' posture, which was infrequently sought earlier. All the four reasoned that sexual act entailed lots of physical energy, which can be avoided by such a posture. Similarly, four men preferred to have regular fellatio only. The spouses were agreeable to occasional oral-genital stimulation, but having the method as the exclusive mode was not acceptable. Two of them felt stifled by the 'unilateralism' of the decision-making and for demanding 'obedience' in the place of 'partner-equality.' Two other patients felt repulsed by their husband's pornographic inclinations, which they had never evinced previously. Viewing pornographic photos or videos was 'unwomanly' and 'no decent woman could stoop to such low levels.' Their husbands felt that such visual stimulation was essential for them to augment their sexuality. One patient demanded that in addition to such videos, the wife should narrate in detail her fantasised sexual acts with whichever man he chose to name. The wife resisted such 'cruel demands' and when forced to, attempted suicide by poisoning. Male erectile disorder and premature orgasm were observed in 10 and four patients respectively and all of them were psychogenic. None of the patients had experienced a lessening of desire. No patient suffered from ejaculatory incompetence or post-coital symptoms.

Certain belief systems which had a cultural sanction, but were at variance with medical opinion were prevalent among these patients (Table 3).

\begin{tabular}{|c|c|c|c|}
\hline & & No & $\begin{array}{c}\text { \% } \\
(\mathbf{n = 4 2})\end{array}$ \\
\hline 1. & Epilepsy causes physical weakness & 32 & 76.1 \\
\hline 2. & Epilepsy causes nervous debility & 28 & 66.6 \\
\hline 3. & Sexual act causes physical weakness & 36 & 85.7 \\
\hline 4. & Sexual act causes nervous debility & 24 & 64.9 \\
\hline 5. & Epilepsy is contagious & 30 & 71.4 \\
\hline 6. & $\begin{array}{c}\text { Epilepsy denoted divine curse and } \\
\text { celibacy is the answer }\end{array}$ & 31 & 73.8 \\
\hline \multicolumn{4}{|c|}{ Table 3. Common Belief-Systems in Relation to } \\
Epilepsy and Sexual Functions \\
\hline \multicolumn{4}{|c|}{}
\end{tabular}

The universal belief that the disease and the long-term drug intake were potentially capable of causing physical weakness, 'nervous debility' and even sudden fatality was correlated to pathological anxiety. Another fear was related to the contagiousness of the illness. Husbands of women patients attributed their new-found extramarital relations to 
such fears and the women felt guilty in 'driving their men to extramarital relations.' Unlike men, two women patients sought extramarital relations 'clandestinely' and 'within the family.' Among men patients, fear of contagion did not curtail their relations with their spouses. Fear of 'divine curse' and the need for expiatory abstinence were thought of by 30 patients, but were not found to be solely pathogenic in even one couple.

\section{DISCUSSION}

Prevalence of the sexual problems among the epileptics was identified against their own individual pattern of pre-morbid sexual behaviour. Corroborative history by the spouses could eliminate false data. Only four out of 42 couples presented with the problem on their own, reflecting the extent of silent morbidity. Studies in the general population have indicated a higher incidence of sexual dysfunction in women. They suffered from lack of desire, arousal problems and genital pains, whereas men evinced lack of desire, erectile dysfunctions and premature orgasms.[13] Prevalence rates in the present study are much at variance with the available statistics in alien cultures.[5][8][10] Non-availability of the native norms for normal pattern of sexual behaviour was a deterrent in interpretation.

The group did not evince clinical evidence of neurological and/or endocrinological impairments. Clinical evaluation and urological investigations ruled out biological causes. Carbamazepine was the most commonly used drug among these patients and could reduce the amount of free testosterone causing decreased libido.[7] But, none of the patients in the present group evinced any loss of desire. None of the patients suffered from significant depressive symptoms.[8]

Clinical impression during interviews that onus of responsibility for sexual behaviour was mostly vested with men was proved by the statistical differences between men and women. Voluntary reduction in frequency, total abstinence and pattern of sexual behaviour were decided by the male members. Husbands of women patients explained their abstinence and extra marital relations through 'fear of contagion' and indulgence was in full knowledge of their wives. Women felt guilty in not meeting the conjugal demands, but extramarital relations of the two women were clandestine and incestuous. Despite the concept of contagion, men patients continued physical relations with their spouses. Sexual activity as culturally sanctioned was always male dominated, male decided, male initiated and male enacted and women played a passive role. Differences in pattern were marked by 'relational problems,' as the focus of concern for women and 'maintenance of dominance' as the theme for men. Doane[14] attributed such differences to the varied roles of anterior cingulate gyrus and the counterbalance between the systems that predominate in men and women.

Emphasis on male superiority adversely resulted in significant anxiety among men. Masculine fears about the weakness and nervous debility caused by both epilepsy and sexual act and the fear of contagion were almost universal. They resorted to voluntary reduction in frequency, occasional total abstinence and reducing the 'physical activity' of sex by women-superior positions and oral-genital gratifications as coping methods. Seeking to reduce the situational anxiety by visual or auditory pornographic stimulation was another method. Yet, beyond such coping strategies, pathological anxiety manifested in sexual dysfunctions. The desire was as before and clinically erectile impotence or loss of erection during the act and premature ejaculation were only psychogenic.

The native belief systems where affect and cognition were synchronously fused formed the basis for the individual's construction and experiencing of sexual pleasure.[15] Though at variance with scientific knowledge and challenged during the interview, they were usually strictly adhered to. Thus, both epilepsy and sexual act were considered as 'energysapping.' The pan-Indian concept of semen as a 'vital force' resulted in the belief that its loss caused physical, psychological and spiritual ill-health. ${ }^{[4]}$ The concept was popularised and given 'scientific sanction' by protagonists of alternate medicine, quacks and even the elite like Gandhiji.[3],[16] At the individual level the unpredictable occurrence, need for long-term management, necessity of day-to-day regularity with drugs and habits provoked persistent anxiety. Subjectively, reinforced by the postictal fatigue, 'weakness' was a major construct in the dynamics of psychogenesis of anxiety.

Epilepsy was viewed as resulting from 'vigorous nervous pulls' and hence caused weakening of the nerves 'including the genital nerves, because seizures entailed urinary incontinence.' Premature ejaculation and erectile impotence 'indicated the range of damage to the genital nerves' and proved the 'nervous weaknesses.'

Concept of contagion was used both as in infectious diseases and in a wider encompassing mode as in 'infectivity of mass hysteria.' But, the fear was real, at least in some patients. The male-female dichotomy was very much evident, with men patients continuing their relations with the wives and women patients being shunned, at times totally. Such native fear of contagion was universal. They were prevalent in Nigeria, Kenya, Ecuador and others and even necessitated burying the epileptic patients separately.[12]

\section{CONCLUSION}

Epilepsy was viewed as 'divine curse.' Sexual renunciation and celibacy have been doctrined across all religions to symbolise the control over body by the soul.[3],[16] But in only three men patients, voluntary reduction as a form of 'truncated celibacy' was cited as a contributory factor. None of the patients practiced celibacy as an expiatory atonement.

The native beliefs were universal in acceptance, but were not uniform in their contribution to the pathogenesis. Thus, the physical weakness and nervous debility were 'here and now' experiences and were more aetiologically contributory. The distantly contemplated and surreal 'curse of the divine' was not found to be a major factor. Though the beliefs were not quoted as being directly aetiological, integrating them and the individual's experiences in the context of culturally assigned roles explained the genesis and maintenance of morbidity in sexual behaviour. Understanding their dynamic relations is an essential necessity for integrated therapeutics. Adequate psychoeducation and counselling of patients and partners will make a huge change in their intimacy and quality of life. 


\section{REFERENCES}

[1] Morris D. The human zoo: a zoologist's classic study of the urban animal. New York: Tokyo: Kodansha Globe 1996.

[2] Bancroft J. Human sexuality and its problems. London: Elsevier Health Sciences 2009.

[3] Caplan P. 10 Celibacy as a solution? Mahatma Gandhi and Brahmacharya. In: Caplan P. The cultural construction of sexuality. London: Routledge 1987;353:271-95.

[4] Sabhesan S, Natarajan M. Sexual behavior after head injury in Indian men and women. Archives of sexual behavior. 1989;118(4):349-56.

[5] Morrell MJ. Sexual dysfunction in epilepsy. Epilepsia 1991;32(Suppl 6):S38-45.

[6] Trimble MR. Neuropsychiatric aspects of epilepsy. Neuropsychiatry 1996:771-803.

[7] Segraves RT. Neuropsychiatric aspects of sexual dysfunction. In: Fogel B, Schiffen S, Roa S. eds. Neuropsychiatry. 1996:757-70.

[8] Hamed S, Mohamed K, El-Taher A, et al. The sexual and reproductive health in men with generalized epilepsy: a multidisciplinary evaluation. Int $\mathrm{J}$ of Impot Res 2006;18(3):287-95.

[9] Murialdo G, Galimberti CA, Fonzi S, et al. Sex hormones and pituitary function in male epileptic patients with altered or normal sexuality. Epilepsia 1995; 36(4):360-5.
[10] Jensen P, Jensen SB, Sørensen PS, et al. Sexual dysfunction in male and female patients with epilepsy: a study of 86 outpatients. Arch of Sex Behav 1990;19(1):1-14.

[11] Stark-Adamec C, Adamec RE. Psychological methodology versus clinical impressions: different perspectives on psychopathology and seizures. In: Doane BK, Livingston KE. eds. the limbic System: functional organization and clinical disorders New York: 1986:217-27.

[12] Shorvon SD, Farmer PJ. Epilepsy in developing countries: a review of epidemiological, sociocultural, and treatment aspects. Epilepsia 1988;29(Suppl 1):S36-54.

[13] Baldwin DS. Depression and sexual dysfunction. $\mathrm{Br}$ Med Bull 2001;57(1):81-99.

[14] Doane BK. Clinical psychiatry and the physiodynamics of the limbic system. In: Doane BK, Livingston KE. eds. The limbic system: functional organization and clinical disorders. New York:1986:285-15.

[15] Scott WA. Attitude measurement. Handbook of Social Psychology. 1968;2:204-73.

[16] Kakkar S. Intimate relations: exploring Indian sexuality. New Delhi: Penguin Books India Pvt Ltd., 1989. 